\title{
Low Carbon Economy and Environmental Finance
}

\author{
Yue Zhang
}

\author{
Yunnan University of Finance and Economics \\ 13211742566@163.com
}

\begin{abstract}
In today's world development, as environmental problems become more and more prominent, the traditional economic model with development as the only goal can no longer meet the development needs. Sustainable and green low-carbon development became the demand of development in all countries. It is a must for China's economic development to complete the important transformation from the traditional model to the low-carbon model. As China's low-carbon finance is lagging behind, the transaction mechanism and market of low-carbon finance are not yet perfect, which brings many inconveniences to the transaction of low-carbon finance in China and even restricts the development of a lowcarbon economy and environmental finance. This paper first analyzes the connotation of low-carbon economy and environmental finance mechanism and related research at home and abroad, then describes the current situation and shortcomings of the development of low-carbon economy and environmental finance mechanism in China, and finally puts forward policy recommendations. According to the low-carbon demand, only by balancing the relationship between economy and environment can society and the country develop benignly.
\end{abstract}

Keywords: economy, finance, environment, low carbon development.

\section{INTRODUCTION}

With the rapid development of industry, and the increasing impact of pollution on normal human life, the development of a low-carbon economy will become a top priority for social progress. The trend of consuming resources and polluting the environment to support economic development will be reversed, and the construction of a green, low-carbon and recyclable economic model will become the mainstream trend of future economic development. In this context, the development of a low-carbon economy and green finance will certainly be a good trend to study. It is also an inevitable choice for an ecologically civilised society at the national and international levels, and a necessary path for further human development. This paper adopts the literature research method to briefly discuss the development of a low carbon economy in China. In the case of China, the country's economic development pursues sustainable development and one can clearly see that the traditional economic development model is unhealthy and has a negative impact on people, therefore, the development of a low-carbon economy is of great significance to the sustainable development strategy and is an important means to build an ecological civilised society. Low-carbon economy is an inevitable trend in the development of enterprises, and an enterprise can only develop healthily in modern society if it truly achieves low-carbon development. The development of a lowcarbon economy will inevitably require continuous progress in science and technology, which will also bring innovation in product technology for enterprises. Thus, the development of a low carbon economy is not only about the environment and climate, but will also bring new vitality to the technology and products of enterprises. This research focuses on a low carbon economy is bound to be at the forefront of similar enterprises. The technological innovation and technological development, which will increase the strength of its products in terms of technology and will seize opportunities in the market, and is extremely important for the development of the enterprise itself, so the development of a low carbon economy is of great significance.

\section{BACKGROUND OF THE LOW CARBON ECONOMY}

Against the backdrop of global warming, the "low carbon economy" based on low energy consumption and low pollution has become a global hotspot. Developed countries in Europe and the United States are vigorously promoting a "low-carbon revolution" with high energy efficiency and low emissions as its core, focusing on the development of "low-carbon technologies" and making 
major adjustments to industrial, energy, technology and trade policies in order to seize the first opportunity and the industrial high ground. At the same time, developing countries also hope to accelerate their economic structural transformation through the development of a low-carbon economy, enhance their international economic competitiveness, grasp the initiative of development and continuously narrow the gap with developed countries. As far as the current development trend of the world is concerned, a new round of technological revolution represented by low-carbon technology is developing vigorously. So in fact, the battle for a low-carbon economy has been fought quietly around the world. The background of the "low carbon economy" is the serious challenge of global warming to human survival and development. As the global population and economy continue to grow, the environmental problems caused by energy use and its causal factors are becoming more widely recognised, not only in terms of smog, photochemical smog and acid rain, but also in terms of global climate change brought about by the rising concentration of carbon dioxide in the atmosphere. This article is in line with China's current efforts to achieve carbon neutrality and carbon peaking.

\section{THE MAIN CONCEPT OF LOW CARBON ECONOMY}

A low-carbon economy refers to a form of economic development that achieves a win-win situation for both economic and social development and ecological environmental protection by minimising the consumption of high-carbon energy such as coal and oil and reducing greenhouse gas emissions through various means such as technological innovation, institutional innovation, industrial transformation and new energy development, under the guidance of the concept of sustainable development. The low-carbon economy is more profitable and has a milder impact on the environment, with specific high efficiency and low energy consumption [1], which also makes it possible to bring considerable economic benefits to the local area while protecting the environment. The low-carbon economy is mainly based on new energy sources such as wind, solar and tidal energy, which bring considerable energy supplements while using natural energy sources [2]. On the other hand, a low-carbon economy cannot replace traditional fuel energy, but it can optimise the structure of traditional fuel use, thus reducing the ability to impact the environment. The development of a low-carbon economy has become the consensus of the world, and many countries, especially developed countries, have taken a low-carbon economy as a high point to cultivate a new national competitive advantage, competing to develop low-carbon technologies and low-carbon industries.

\section{CONTEMPORARY SITUATIONS FACED BY LOW CARBON ECONOMY AND ENVIRONMENTAL FINANCE}

\subsection{The opportunities presented}

For finance, the concept of a low-carbon economy promoted today points to a new path for finance. Unlike traditional laws, the low-carbon economy is an economic policy proposed by the government, and its sustainability and foundation are undeniable. This is a once-in-acentury opportunity for finance [3]. Finance will be able to move forward for at least a century without being affected by other trends in business values, as long as it can follow the trend of the times. In other words, the low carbon economy reduces the control of venture capital in finance to a minimum level. Also with the advent of carbon finance as well as green credit, small businesses are starting out protected by initial funding and markets.

\subsection{Setbacks encountered}

Difficulties in the transformation of financial institutions The low-carbon economy not only brings opportunities for finance, but also poses some challenges to it [4]. Today's finance usually relies on traditional and more stable business structures, which are still far from the goals required by the low-carbon economy. Finance actually represents a transfer of capital, which has little real value in itself and therefore often needs to rely on a more mature capital base. If you want to move away from the traditional financial model, then you need to disassociate yourself from traditional capital in order to engage in a low carbon economy. In practice, this is very difficult and small financial institutions are unable to make this transition because their capital flows do not allow them to complete their gaps in the base, which makes them dependent on the traditional financial model. In fact, some financial institutions are unable to enjoy the benefits of the low-carbon economy, and there are only two options available to them. The first is to transform the financial structure as soon as possible in order to minimize losses. The second is to extend the life of its idiosyncratic traditional financial structure and try to avoid disappearing into the contemporary era.

There are more regulatory loopholes and the relevant regulations are not sound enough though China now has laws in place in a low-carbon economy, such as the Law on the Promotion of Circular Economy, the Law on Energy Conservation and other related laws, the coverage of these laws also remains limited, and basically cannot play an effective role in the face of the rapidly changing financial environment [5]. Innovative countermeasures in low carbon economy and environmental financel. Promote the optimization of technology within the industry and adjust the economic ratio. 
The development of a low-carbon economy, compared with the industrial revolution, does not have a high technological upgrading capacity, but rather requires certain concessions of technology, which makes some fast financing not interested enough in a low-carbon economy, and also indirectly leads to the financing difficulties of low-carbon financial structure, so promoting the technological replacement between industries and optimizing the resource structure in industries becomes the first thing to do in a low-carbon economy. In this process of technology optimization, major financial institutions can try to enter funds into the bottom part of technology renewal, which will not only promote technology reform but also increase the dependence of small institutions on funds, which also creates a basis for deeper cooperation in the future [6]

\subsection{Building an information sharing platform}

Because the low-carbon economy itself is only an external attribute of capital, it involves different industries in most cases, and its span is also wide, with more obvious information differences. The inequality of information will lead to the lack of judgment of professional knowledge of financial capital, which will lead to the inability of accurate inflow of capital. Relatively, small and medium-sized enterprises will also be unable to receive the inflow of funds from financial institutions, which will also affect the operation of their capital chains, thus leading to the inability of the three ends to cooperate accurately. Therefore, the first thing that low-carbon economy financial institutions should do is to build shared platform information, and improve and maintain it regularly. The construction of the shared platform information can help banks make correct judgments, which can reduce the venture capital concerns of financial institutions, thus enabling better financing for small and medium-sized enterprises.

\subsection{Establishing a correspondence system and building an environmental finance market with different dimensions}

In the process of designing exclusive tools for environmental finance, the first thing is to lower the threshold for institutions to enter, so that some small and medium-sized institutions can smoothly invest in economic finance and so on. But before that a good environmental information audit system should be established so that the economic structure of small and medium-sized institutions can be analyzed when they are admitted. In addition to this a green credit business can be set up, this kind is mainly aimed at small business institutions that do not have the ability to carry out low carbon reforms in order to help them to successfully transform and thus increase the market share of real estate finance [7]. The stateside can also actively help free economic financial institutions to carry out related financial work, such as carrying out green bonds, lowcarbon insurance and other related ways to stimulate the inflow of funds into economic finance, so as to enhance the basic strength of economic finance in order to be able to adapt to the economic impact from the traditional financial structure. In fact, the most ideal state is the combination of the national low carbon economic structure and the socio-economic talk about the economic structure in order to cope with the market shocks at different levels. For example, in the domestic economic environment, because the overall economic share of the low-carbon economy is still low, it can rely on the national economic finance to increase its market share. In addition, the government should also try to restrict the old carbon market, such as strengthening the supervision of petroleum fuels., and we shut down enterprises with high carbon emissions, this can make the market economy appear a kind of this and that, and give an implication of the psychological growth of a low-carbon economy mainly [8].

\subsection{Improve the corresponding laws and regulations}

Although China said that it has made a lot of laws on the low-carbon economy, there is still a significant gap compared with those developed countries. However, this is not an overnight work, China's market environment is more complex and also has greater resources, so it also needs a longer time to make up the loopholes of the law. During the development of the law, the government can try to guide the values of low carbon economy towards enhancing people's self-confidence in the low carbon economy, thus reducing the pressure of low carbon economy development [9]. However, this is not a longterm solution, and the establishment of a sound legal system can better help the development of a low-carbon economy and can also provide some restraint to the traditional fuel financial institutions.

\section{CONCLUSION}

China's economic development needs to be accompanied by environmental enhancement to truly obtain long-term benefits. In the process of advocating sustainable development strategies, a low-carbon economy can help alleviate market pressure and moreover maintain a balance between ecology. Reducing energy consumption and promoting the deepening of the implementation of sustainable development strategy can truly make the development of a low-carbon economy meet the requirements of China's national development, and can make the development of green economy more in line with the requirements of resource-based development, and by promoting the balanced development of green financial development, China's green industry can solve the financial financing problem to make the development of green finance more smooth, 
so that the green economy can truly promote China's progress in the new era, to green development to advocate the strategic construction of China's economic development process.

\section{REFERENCES}

[1] Li Xian Deng. Low carbon economy and environmental finance innovation $[\mathrm{J}]$. Business Intelligence, 2018(07):49.

[2] Sun Maoxin. Research on financial support for the development of low-carbon economy [J]. Finance and Accounting Learning, 2017(23): 214.

[3] Li Zexin. Research on financial and fiscal support for low-carbon economic development [J]. Global Market Information Herald, 2017(13): 36.

[4] Liu Fengxia. Exploring the effective combination between low-carbon economy and finance [J]. China Science and Technology Investment, 2018(16): 219.

[5] Huang W. Research on the relationship between financial development, innovation level and economic growth - taking the Yangtze River economic belt as an example [J]. Old brand marketing, 2020(02): 42-43.

[6] Tie Zheng;;Forest is the largest organic carbon reservoir $[\mathrm{A}]$; Theory of low-carbon economy and forestry development--Chinese Forestry Academic Forum-6th series [C];2009

[7] Lu, Liangxia; Wen, Bing; Research progress of inefficient forest stand transformation in China from the perspective of low-carbon economy [A]; Forestry technology and management innovation in the era of low-carbon economy [C]; 2010 